\title{
Investigation of Mechanical Properties of AISI 316 Stainless Steel by Carbonitriding Process
}

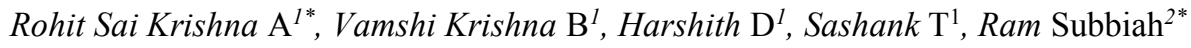 \\ ${ }^{1}$ Under Graduate Students, Gokaraju Rangaraju Institute of Engineering and Technology, Hyderabad, India \\ ${ }^{2}$ Associate Professor, Gokaraju Rangaraju Institute of Engineering and Technology, Hyderabad, India
}

\begin{abstract}
This project investigates on salt bath nitriding process in order to improve the wear behavior of the material. This process increases the hardness of the material. The specimens were nitrided at $580^{\circ} \mathrm{c}$ on three different timing hours such as 60 minutes, 90 minutes \& 120 minutes. A pin on disc machine is used to conduct wear test, so that wear loss can be determined. The specimens are to be magnified by metallographic test like scanning electron microscope. The untreated specimen is used to compare with the nitrided specimen. The best specimen is chosen which determines the life of material \& improves the better wear resistance. The hardness of untreated material and nitrided material are compared. The material AISI stainless steel has many unique properties but it lacks wear resistance and hardness because of which it has limited applications. By conducting heat treatment operation, the hardness of the material does not improve, but by conducting case hardening process the hardness of the outer case will be high compared to base metal. If the hardness and wear resistance of the material improves the material can be used in wide range of applications.
\end{abstract}

\section{Introduction}

Stainless steels are modern steel materials. As the name derives the material is corrosion resistant and it is the main property which makes it unique compared to other metals. Stainless steel is defined as a ferrous alloy which has a minimum of $10 \%$ chromium content, which ensures the presence of self-healing oxide on the layer which resists the material against corrosion [1-3]. As this steel does not stain, rust or corrode as easily as other steel it is known as stainless steel. It is also known as corrosion resistant steel unless the detailed description or the grade name is not specified, particularly in aviation industry. There are number of different grades in stainless steel which as selected according to the requirement of working environment [4-6].

Stainless behavior, less maintenance, low cost makes this metal ideal for wide range of economical applications. It is $100 \%$ recyclable. To use stainless steel in construction field, it is necessary to know its properties, its capabilities regarding erosion resistance and also the availability of the material types and its finished surface [7,8]. Treated steel has wide scope of applications, it can be used for applications that require erosion resistance and heat resistance. The grade will be selected according to the requirement of the work place. The metal is processed into sheets, plates, bars, wires, and tubing to be used in cookware, cutlery, equipment, careful instruments, significant apparatus, modern gear and antiquity in high rises and huge structures. Most common uses of stainless steel are "spoons" or "watches straps" and house hold appliances. Stainless steels have high protection from oxidation and consumption in numerous normal and artificial situations $[9,10]$. In any case, it is critical to choose appropriate evaluation of tempered steel which suits the application. In some ways stainless steels are unexplored to the earth, but to know the advantages more properties has to be studied.

Steel is a composite whose significant segment is iron and it has carbon content going somewhere in the range of $0.02 \%$ and $1.7 \%$ by weight, based on grade. In metallurgy chrome steel [11], additionally alluded as inox steel from "inoxydable", is characterized as a metal combination which has chromium content with at least 10.5 or $11 \%$ by mass. Chrome steel doesn't recolor, consume, or rust as effectively as common steel, yet it's not stain-confirmation [12-13].

Chrome steel contrasts from steel by the measure of chromium present. Unprotected steel rusts instantly when introduced to atmosphere. This iron oxide film in like manner called as rust is dynamic, expands the advancement of disintegration, and structures more utilization. Hardened steels contain adequate chromium to make an inactive film of chromium oxide, which forestalls arrangement of erosion further in the inner structure [14-16]. 


\section{Experimental Procedure}

All the experiments are performed in a Salt bath nitriding furnace maintained at $580^{\circ} \mathrm{C}$ constant temperature by varying time of experimentation for detailed comparison purpose

Table 1: Chemical Composition

\begin{tabular}{|l|c|}
\hline \multicolumn{1}{|c|}{ Metals } & Composition (\%) \\
\hline Carbon & $0.03 \%$ \\
\hline Manganese & $1.93 \%$ \\
\hline Silicon & $0.56 \%$ \\
\hline Sulphur & $0.017 \%$ \\
\hline Phosphorous & $0.021 \%$ \\
\hline Nickel & $12.24 \%$ \\
\hline Chromium & $17.94 \%$ \\
\hline Molybdenum & $2.06 \%$ \\
\hline
\end{tabular}

For performing the heat treatment operation on AISI 316 Austenitic stainless samples, four specimens of $40 \mathrm{~mm}$ length and $10 \mathrm{~mm}$ diameter are cut and surface finished from long stainless-steel rod. These samples are subjected to turning to get bullet shape so that the tip of specimens would completely touch the pin on disc during wear test, which would generate better wear on specimen surface for SEM and XRD analysis. After setting up the furnace to required conditions, the Ammonia salts are introduced into container. This salt solution is allowed to dissolve completely in furnace so that no scale formation takes place on the walls $[17,18]$. The AISI 316 specimens are tightly held together in a cage and placed in Salt bath furnace as shown in Fig 3. As the temperature constantly increases, the specimens are allowed to develop a nitrided layer. Now, the experimentation timing is varied accordingly for all four samples by taking out sample from furnace after every 30 minutes. Therefore, the time of heat treatment is varied by 60 minutes, 90 minutes and 120 minutes accordingly for three specimens while one is left untreated for comparing SEM and Wear test results. The main objective of developing a case depth of nitrogen is achieved which varies between samples due to time variation. The longest treated specimen develops a large case depth while the least treated specimen develops smaller case depth. After completing heat treatment process, the specimens are prepared for wear test on pin on disc apparatus. The sample is held in the pin position by fixtures with help of suitable mechanical tightening tools [19-20].

The diameter of disc is $110 \mathrm{~mm}$ which is made up of high-speed stainless-steel material. The speed of rotation is set to 600rpm and a load of $10 \mathrm{~N}$ is applied constantly on disc by pin. When apparatus is switched on, the pin is allowed to make contact with disc vertically such that the specimen tip entirely touches it.
The elastic pivoted arm enables to vary the pin position on disc by moving in three-dimensional plane. The disc is rotated for a time period of two minutes for all specimens. First the untreated specimen is subjected to wear test, subsequently the remaining specimens i.e., $60 \mathrm{~min}$ treated specimen, $90 \mathrm{~min}$ treated specimen and 120 min treated specimen are subjected to wear test on pin on disc equipment. A graph is plotted between applied frictional force $(\mathrm{N})$, Wear generated(mm) and time(s) for all the samples during the experiment.

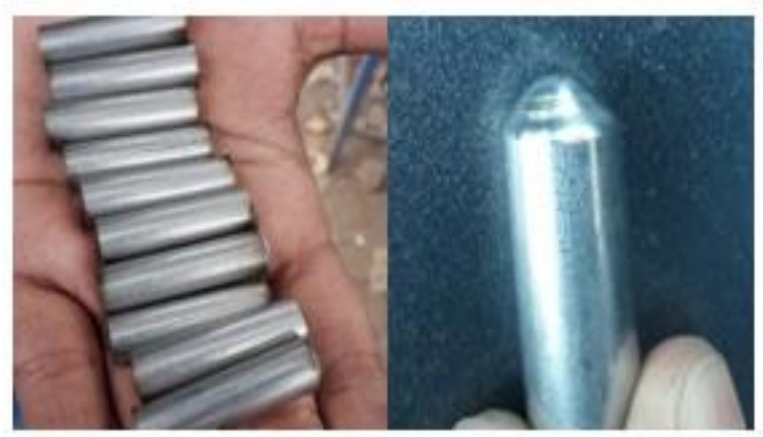

Fig. 1. AISI Austenitic stainless steel fractured into pieces and machined in bullet shape

The maximum wear developed in specimen is depicted in graph along with track diameter and load applied. Further, the SEM analysis is done on the samples before and after wear test to compare the mechanical properties, microstructure and case depth developed. The furnace for three different time intervals. One specimen upto 60 minutes 2 nd pair upto 90 minutes and the last pair upto 120 minutes. The furnace contains salt bath solution which contains more amount of ammonium and less carbon content [7-8].

Here the material AISI 316 stainless steel is cut into 8 pieces with length $40 \mathrm{~mm}$ and diameter $10 \mathrm{~mm}$ as shown in Fig 1. These specimen is machined in the form of bullets so that while doing wear test the surface of the specimen will have proper contact with the disc.

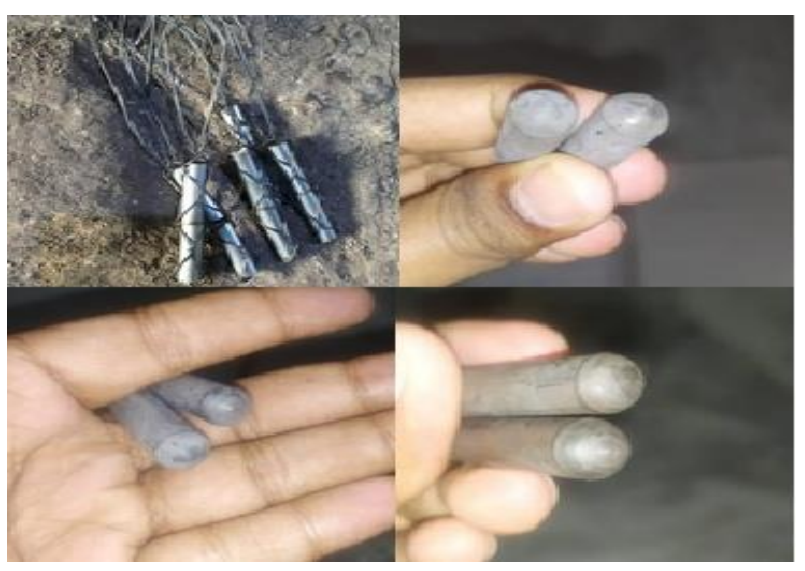

Fig. 2. untreated specimen and specimens treated for 60 minutes, 90 minutes and 120 minutes. 


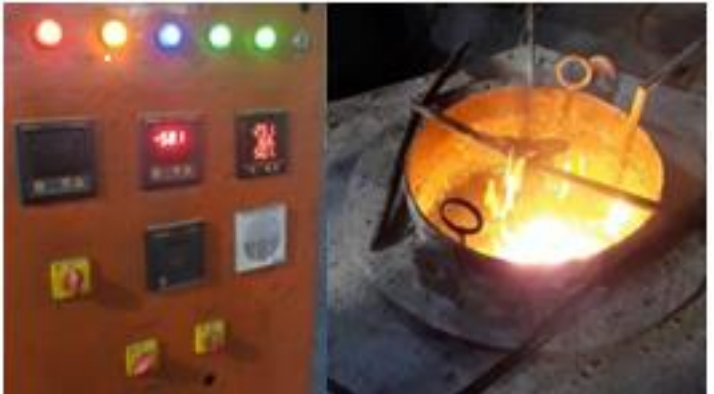

Fig. 3.Digital temperature indicator and Controller

A pair of specimen is divided into four sets and one is kept as untreated and the remaining specimen is kept in Then SEM images of the specimen is taken to see the microstructure of the specimen as shown in Fig 2 . Using Pin on disc wear testing machine wear test is conducted, for which we use wear and time, frictions and time as parameters to check the wearas shown in Fig 4. Then again SEM images of the surface which is subjected to wear is taken to check the microstructure. Hardness of the specimen before and after wear is also checked using Vickers hardness testing machine and was found to be $1080 \mathrm{Hv}$, Whereas in an untreated sample the hardness was found to be $330 \mathrm{Hv}$ [8-10].

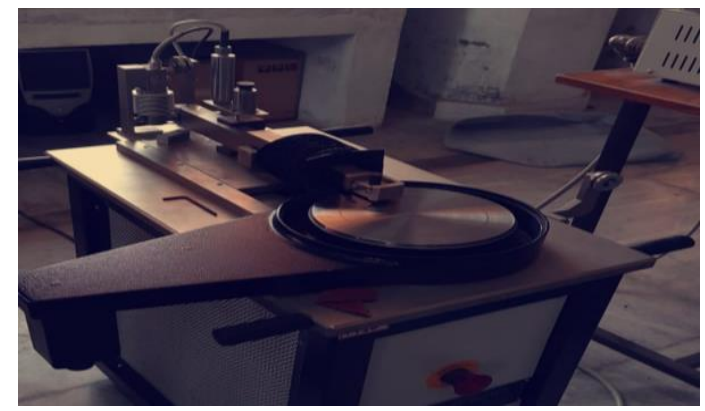

Fig. 4.Pin on disc wear testing machine

\section{Results and Discussion}

The results were compared with scanning electron microscope images. It was found to be that, due to the action of load and variation in friction, the wear loss was found to be less in treated specimen, whereas it was high in an untreated specimen. This is the untreated sample, as it is machined the surface is rough. The grey surface indicated the base metal as shown in Fig 5.

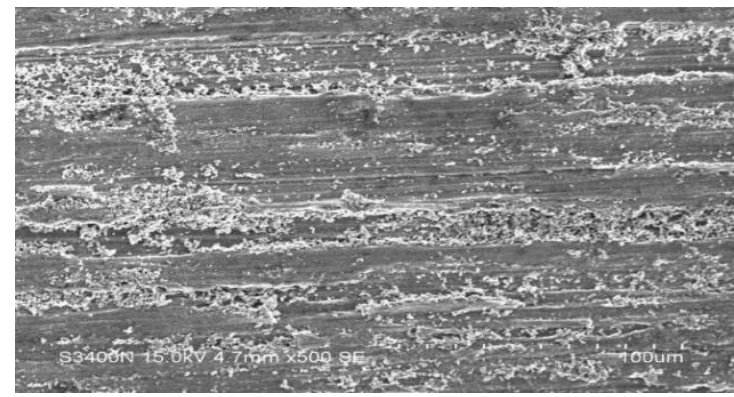

Fig. 7. SEM image of specimen treated for 90minutes
The specimen treated for 60 minutes in a salt bath at temperature of $580^{\circ}$. Here the Grey surface is the base metal and the white particles are the precipitates of nitrogen. Here the grain structure is less coarse compared to untreated sample as shown in Fig 6.

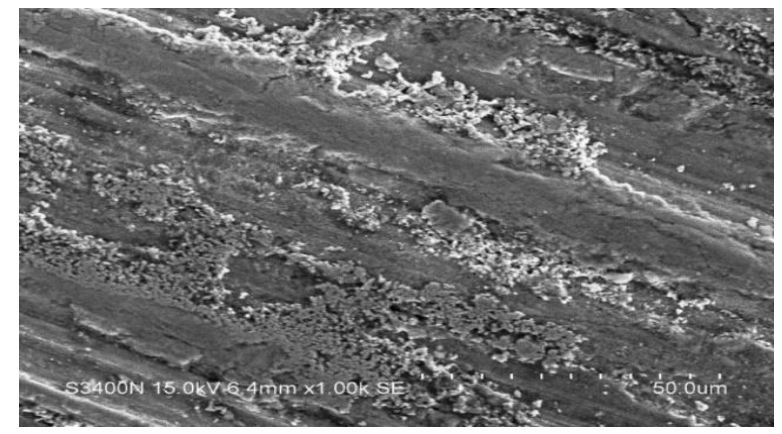

Fig. 6.SEM image of specimen treated for 60 minutes

The SEM image of specimen treated for $90 \mathrm{~min}$. The grey surface is the base metal and the white particles are the precipitates of nitrogen. Compared to the specimen treated for 60 minutes this specimen has partially fine nitrogen grain structure as shown in Fig 7.

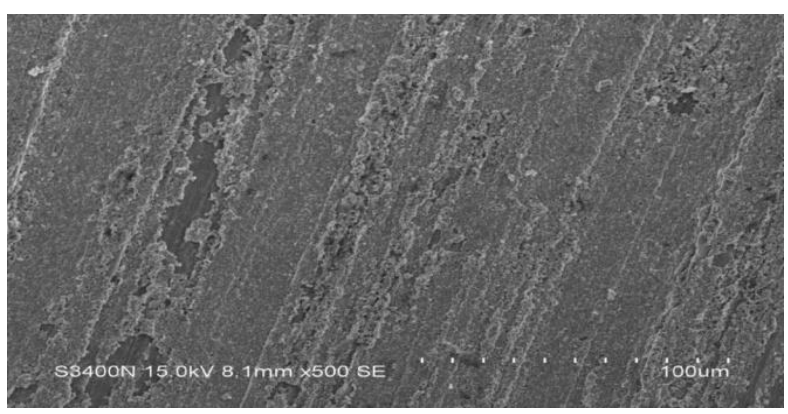

Fig. 7.SEM image of specimen treated for 90minutes

This is the SEM image of specimen treated for 120 min. The grey surface is the base metal and the white particles are the precipitates of nitrogen. Compared to the specimen treated for 90 minutes this specimen has fine nitrogen grain structure as shown in Fig 8

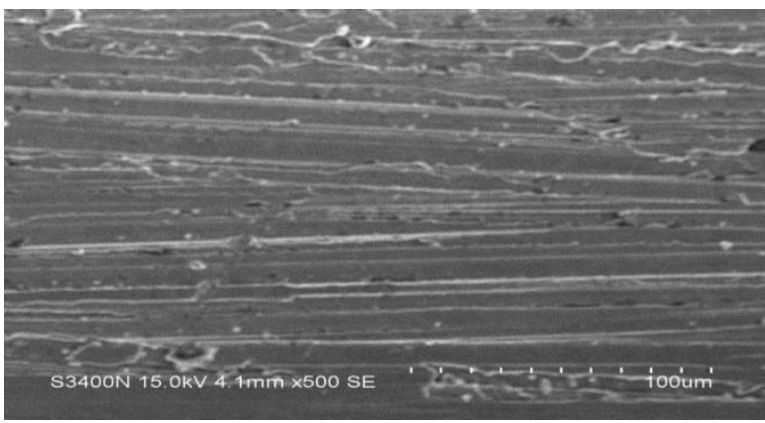

Fig.8.SEM image of specimen treated for $120 \mathrm{~min}$ 's

The wear resistance of the metal (AISI 316) is happens to be improved with the Carbonitriding process only when the material undergoes load for shorter intervals of time. This tells us that by using Carbonitriding process AISI 316 can perform well in the applications where there is load for shorter intervals.

From the plot results obtained during wear test the wear on the specimens has many fluctuations with the 
variations in the timing of Carbonitriding process. The wear is more in the Carbonitrided specimens when the hardened surface undergoes wear. However, there is an improvement in the wear resistance of Specimen that is treated for 120 minutes when compared to all the other specimens.

From this analysis, we observed that a whitish hardened layer is formed upon performing Salt bath nitriding process. As the duration of salt bath nitriding process increases the whitish layer happened to be more this indicates us that more the duration of process higher concentration of carbon nitrogen atoms were diffused on to the surface. The surface finish is also increased from untreated specimen to the specimen treated for 120 minutes.

\section{Conclusion}

The study done so far was to investigate the mechanical properties of AISI 316 Stainless Steel when it is arbonitrided at different timings. Mechanical properties, here we are concentrating on mainly on Wear resistance of the material. The motive behind carrying out this experiment is to perform Carbonitriding process on the specimens which is a case hardening process that develops a hardened layer of thickness about 2 microns to 3 microns on the surface of metal.

The following conclusions are made based on the Experiments and tests conducted. It is known that stainless steel has good corrosion resistance with the presence of molybdenum and it is available abundantly in the market. Even though it has many advantages over other metals but it is not recommended in some applications because of its less hardness. Therefore, our intention is to make this metal used in wide range of applications like Oil pits, chemical Industries, Gas supply pipelines by enhancing its properties.

AISI 316 Stainless steel is in Austenitic phase it cannot be Heat Treated. Therefore, the surface hardening processes are feasible to modify its Mechanical properties.Upon performing salt bath Nitriding a thin hardened layer is formed on the surface of metal, this layer thickness is proportional to the duration of Carbonitriding process. The layer formed here in 120minute duration is from 2 to 3 microns.

\section{References}

1. H. Baba, T. Kodama, T. Katada, vol.1, pp. 23932397.

2. S. Balaji,P. Vijay and A. Upadhyaya, ScriptaMaterialia, pp.1-4, (2007).

3. A. Ramachandani and J.K. Dennis, Heat treatment of metals pp.34-38, (1988).

4. Y. Sun, T. Bell, Wear pp. 34-42, (1998).

5. Rajagiri A, MN Sandhya, Nawaz S, Suresh Kumar T, E3S Web of Conferences 8701004 (2019).

6. K.G. Budinski and M.K. Budinski, 7 th Edition, Engineering Materials, Prentice Hall India Ltd, (2006).
7. R. James, Easterday, (2001).

8. K. Funatani,Vol 46, No 8, pp, 277-281, (2004).

9. I. Olefjord,L. Wegrelius, Corrossci; 38(7):pp 120320. (1996).

10. T. Bell,Surface Engineering, Vol 18, No 6, pp 231237, (2002).

11.Baloji, D., Anil, K., Satyanarayana, K., Singh, S. K., \& Naik, M. T. Material Today 18, 4475-4481. (2019)

12.V. Vignal, S. Ringeval, S. Thiébaut, K. Tabalaiev, $C$. Dessolin, O. Heintz, F. Herbst, R. Chassagnon, Corrosion Science, Volume 85, Pages 42-51, (August 2014).

13. C.R. Das, A.K. Bhaduri, G. Srinivasan, V. Shankar, S. Mathew,Journal of Materials Processing Technology, Volume 209, Issue 3, Pages 1428-1435, (1 February 2009)

14.B. Qin, Z.Y. Wang, Q.S. Sun, Materials Characterization, Volume 59, Issue 8, Pages 10961100, (August 2008).

15. Suresh Kumar Tummala, Dhasharatha G, E3S Web of Conferences 87, 01030 (2019)

16. Jae-Gil Jung, Minsu Jung, Sang-Min Lee, Eunjoo Shin, Han-Chul Shin, Young-Kook Lee, Journal of Alloys and Compounds, Volume 553, Pages 299-307, (15 March 2013).

17. XuesongXiong, Feng Yang, Xingrong Zou, Jinping Suo, Journal of Nuclear Materials, Volume 430, Issues 1-3, Pages 114-118, (November 2012).

18.Zhao-Xi Wang, FeiXue, Jia-Wang Jiang, Wen-Xin Ti, Wei-Wei Yu, Engineering Failure Analysis, Volume 18, Issue 1, Pages 403-410, (January 2011).

19. Manikonda, R. D., Kosaraju, S., Raj, K. A., \& Sateesh, N., Material Today 5, 20104-20109. (2018)

20. Hamid Reza Bakhsheshi-Rad, Ahmad Monshi, Hossain Monajatizadeh, MohdHasbullah Idris, Mohammed Rafiq Abdul Kadir, Hassan Jafari, Journal of Iron and Steel Research, International, Volume 18, Issue 12, Pages 49-56, (December 2011). 